\title{
Wall shear stress in the development of in-stent restenosis revisited. A critical review of clinical data on shear stress after intracoronary stent implantation
}

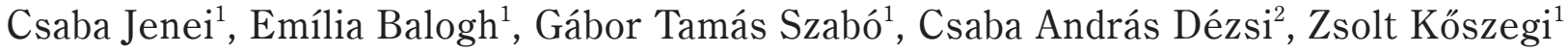 \\ ${ }^{1}$ Institute of Cardiology, University of Debrecen, Debrecen, Hungary \\ ${ }^{2}$ Department of Cardiology, Petz Aladár County Teaching Hospital, Győr, Hungary
}

\begin{abstract}
The average wall shear stress (WSS) is in 1 Pa range in coronary arteries, while the stretching effect of an implanted coronary stent can generate up to $3 \times 10^{5}$ times higher circumferential stress in the vessel wall. It is widely accepted that WSS plays a critical role in the development of restenosis after coronary stent implantation, but relevant clinical endpoint studies are lacking. Fluid dynamics modeling suggests an association between WSS and intimal hyperplasia, however, such an association is not established when the compensating healing process becomes an overshoot phenomenon. This review summarizes available clinical results and concepts of potential clinical importance. (Cardiol J 2016; 23, 4: 365-373)
\end{abstract}

Key words: wall shear stress, percutaneous coronary intervention, stent implantation, in-stent restenosis

\section{Introduction}

The coronary artery wall is exposed by two main loads: the frictional force of the blood flow and the blood pressure (BP). The flow results in wall shear stress (WSS) in tangential direction while BP acts perpendicular to the vessel wall and generates the circumferential stress according to the Laplace's law. The reported value of the physiological shear stress was approx. $1 \mathrm{~Pa}$, while the circumferential stress was approx. $100-150 \mathrm{kPa}$ assuming normal BP. In case of stent implantation in a narrowed coronary artery, further wall stress will be generated by the stent which can reach a value of $300 \mathrm{kPa}$, being 5 orders of magnitude higher than the flow-generated shear stress $[1,2]$.

There are several publications reporting follow-up data about the relation between WSS and the progression of the native coronary lesions fol- lowing coronary stent implantation. It is generally accepted that endothelium is extremely sensitive to the WSS, producing anti-atherogenic substances (e.g., nitric oxide). Low and oscillatory shear stress conditions are pro-atherogenic and lead to atherosclerotic plaque formation [3-7].

The proposed mechanism involves mechanoreceptors in membrane of endothelial cells, e.g. receptor tyrosine kinase, such the vascular endothelial growth factor receptor (VEGFR) and adhesion molecules (such as platelet endothelial cell adhesion molecule [PECAM-1]). Shear stress also influences activation of endothelial cells through multiple mechanisms that target mitogenactivated protein kinases, nuclear factor-kappa-B, and endothelial nitric oxide synthase. Low shear stress can trigger intracellular cascades and shift phenotypic endothelial cell expression to an atherosclerotic prone state. Such endothelial cells display

Address for correspondence: Prof. Csaba András Dézsi, Department of Cardiology, Petz Aladár County Teaching Hospital, Vasvári P. str. 2-4, Győr 9024, Hungary, tel: +36-96418244, e-mail: dcsa62@gmail.com 


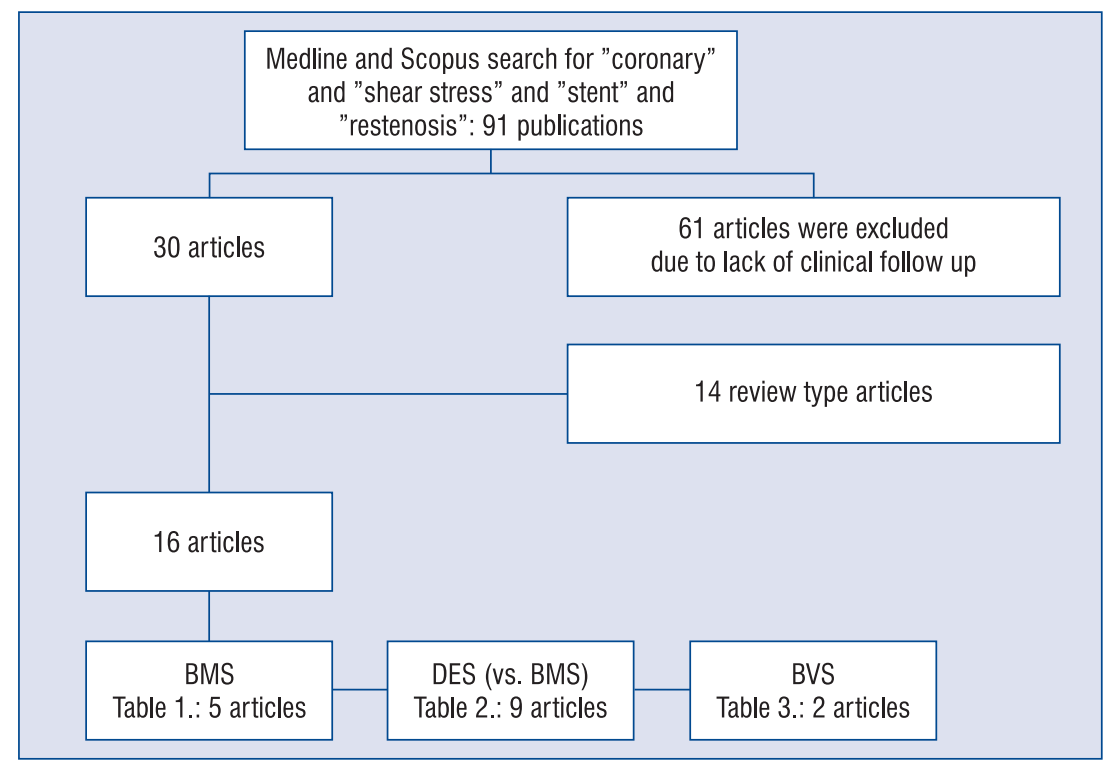

Figure 1. Flow chart of the selection of articles for review; BMS — bare metal stent; BVS — bioabsorbable vascular scaffold; DES — drug eluting stent.

enhanced expression of inflammatory molecules and higher rates of apoptosis [8-10].

According to already published data, the average WSS in coronary arteries during resting condition ranges from $0.5 \mathrm{~Pa}$ to $7 \mathrm{~Pa}$ and depends on the applied calculation method. Pathologically low WSS with values below $0.5-1 \mathrm{~Pa}$ has been reported to induce plaque formation. Besides the average WSS, it is also believed that the direction and oscillation of tangential friction also play a role in adverse intimal processes $[11,12]$.

Stent implantation results in acute mechanical damage to the vessel wall, initiating several platelet and inflammatory reactions. Later these processes lead to proliferation and migration of smooth muscle cells (SMCs) with accompanying formation of the extracellular matrix. In the case of standard re-endothelialization of the stented arterial segment, this healing process stops after the stent struts are covered with neointima, while an overshoot of the regeneration can progress to restenosis [13, 14].

In experimental models, shear stress clearly affects the migratory and proliferative responses of SMCs $[15,16]$; clinical studies also indicate a correlation between intimal hyperplasia and low shear stress. However, data regarding systematic follow-up investigation and WSS calculation after stent implantation in large patient populations remain limited in number. This critical review summarizes the available data from human follow- up investigations and the proposed mechanisms underlying the effect of stent implantation on WSS, as well as the subsequent WSS-induced neointimal processes.

\section{Methods}

The main criteria for inclusion in this review were calculation of WSS in human coronary arteries and corresponding follow-up invasive investigation. PubMed and Scopus databases were searched for relevant articles published between January 1990 and October 2015 using a search strategy based on text words. The search string comprised "coronary", "shear stress", "stent", and "restenosis." The publications found were evaluated according to the involvement of human follow-up investigations. Articles not reporting repeated invasive assessment of stent implantation were rejected, as well as review articles not containing original observations. The remaining studies were classified according to the implanted stent type: bare-metal stent (BMS), drug-eluting stent (DES), or bioresorbable vascular scaffold (BVS) (Fig. 1).

Data were extracted and tabulated in a structured form showing parameters of the publications, number of observed patients, modality of coronary imaging, method of flow calculation, assumed flow, duration of follow-up, and main clinical findings (Tables 1-3). 


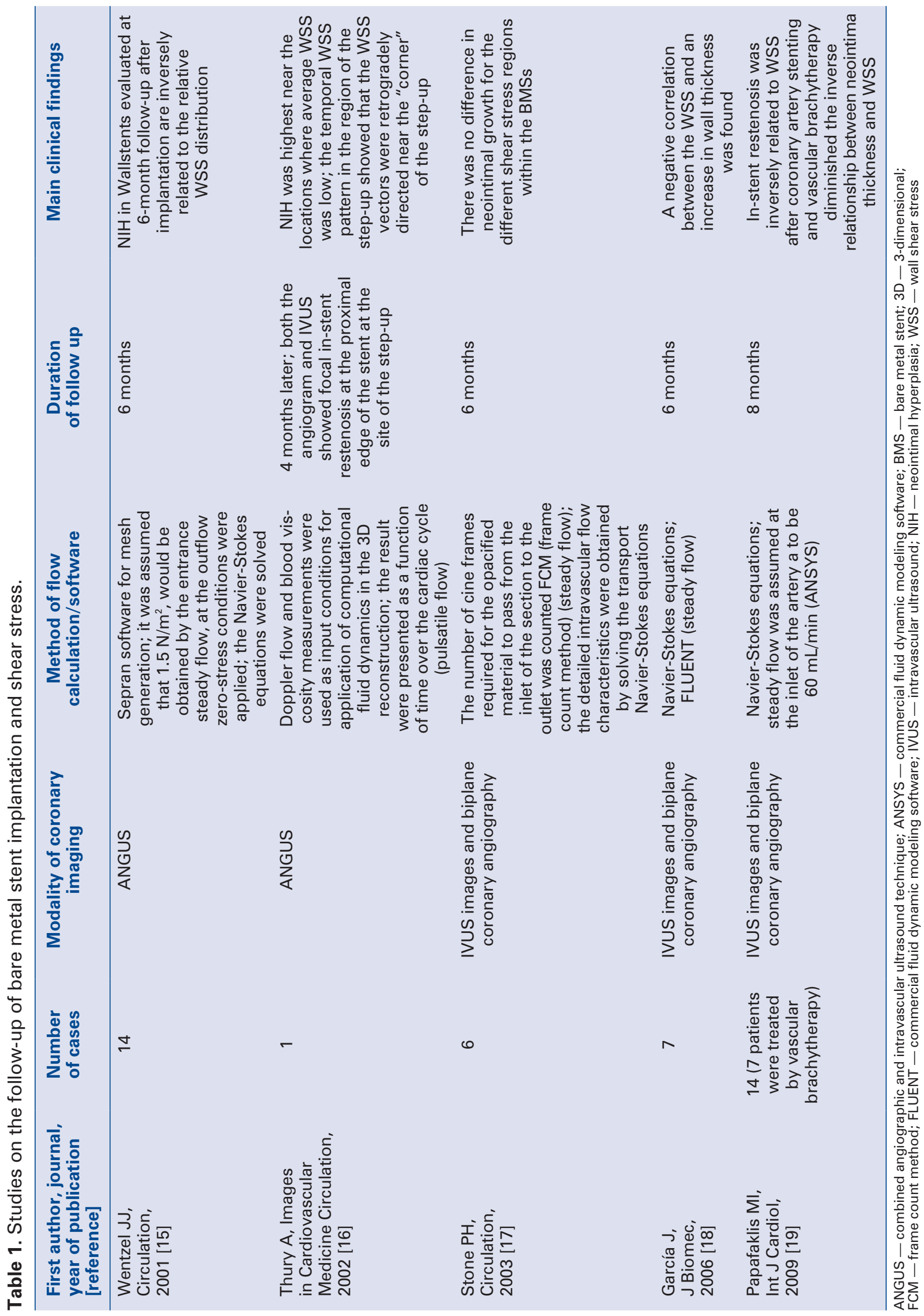




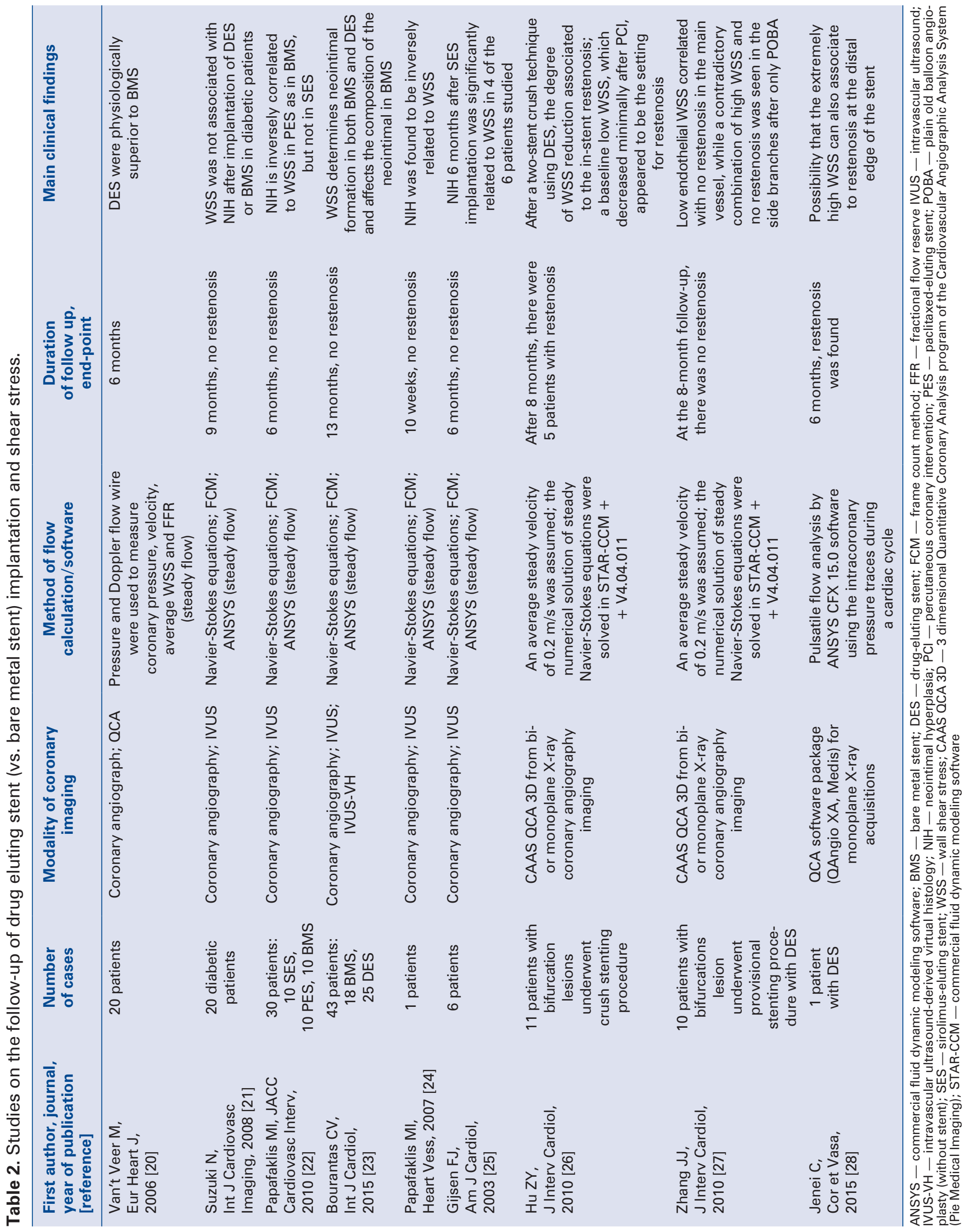


Table 3. Studies on the follow-up of bioabsorbable vascular scaffold implantation and shear stress.

\begin{tabular}{|c|c|c|c|c|c|}
\hline $\begin{array}{l}\text { First author, journal, } \\
\text { year of publication } \\
\text { [reference] }\end{array}$ & $\begin{array}{l}\text { Number } \\
\text { of cases }\end{array}$ & $\begin{array}{l}\text { Modality } \\
\text { of coronary } \\
\text { imaging }\end{array}$ & $\begin{array}{l}\text { Method of flow } \\
\text { calculation/ } \\
\text { /software }\end{array}$ & $\begin{array}{l}\text { Duration of follow } \\
\text { up, clinical } \\
\text { end-point }\end{array}$ & $\begin{array}{l}\text { Main clinical } \\
\text { findings }\end{array}$ \\
\hline $\begin{array}{l}\text { Papafaklis MI, } \\
\text { Eurolntervention, } \\
2013 \text { [29] }\end{array}$ & 1 & $\begin{array}{c}\text { Coronary } \\
\text { angiography; } \\
\text { IVUS; OCT }\end{array}$ & $\begin{array}{l}\text { Navier-Stokes } \\
\text { equations; } \\
\text { FCM; ANSYS }\end{array}$ & 6 months & $\begin{array}{c}\text { The relationship } \\
\text { between baseline } \\
\text { WSS and 6-month } \\
\text { neointimal thickness } \\
\text { was much stronger } \\
\text { in the OCT based 3D } \\
\text { reconstruction than } \\
\text { in the IVUS based } \\
\text { calculation }\end{array}$ \\
\hline $\begin{array}{l}\text { Bourantas CV, } \\
\text { JACC Cardiovasc } \\
\text { Interv, } 2014 \text { [30] }\end{array}$ & 12 & $\begin{array}{c}\text { Coronary } \\
\text { angiography; } \\
\text { OCT }\end{array}$ & $\begin{array}{l}\text { Navier-Stokes } \\
\text { equations; } \\
\text { FCM; ANSYS }\end{array}$ & 12 months & $\begin{array}{l}\text { An inverse association } \\
\text { between WSS and } \\
\text { NIH was found after } \\
\text { Absorb BVS } \\
\text { implantation as } \\
\text { a consequence } \\
\text { of local hemodynamic } \\
\text { milieu on vessel } \\
\text { wall healing }\end{array}$ \\
\hline
\end{tabular}

ANSYS - commercial fluid dynamic modeling software; BVS - bioabsorbable vascular scaffold; 3D - 3-dimensional; FCM - frame count method; IVUS — intravascular ultrasound; NIH — neointimal hyperplasia; OCT — optical coherence tomography; WSS — wall shear stress

\section{Results}

Studies concerning the measurement of neointimal hyperplasia (NIH) during a follow-up investigation in relation to evaluation of the shear stress after BMS implantation are summarized in Table 1. Tables 2 and 3 report the available data regarding DES and BVS. It is clear from the "Modality of coronary imaging" columns that intravascular ultrasound (IVUS) was the most frequent tool for the detection of NIH for the BMS and DES studies, while optical coherence tomography was necessary for the appropriate assessment of BVS results. The methods for calculation usually assumed a steady flow, therefore an average of the WSS during the cardiac cycle was determined.

\section{BMS studies}

Wentzel et al. [15] published a human in vivo study of the effect of shear stress on NIH in 14 coronary arteries 6 months after a Wallstent implantation. The average relationship between neointimal thickness and shear stress was as follows: neointimal thickness $=(0.59 \pm 0.24)-(0.8 \pm$ $\pm 0.10) \times$ WSS $[\mathrm{mm}](\mathrm{p}<0.05)$. The resulting data showed that neointimal growth occurs in regions of low shear stress [15].

In a case report, Thury et al. [16] also found the highest NIH at the locations where average WSS was low. He detected a focal in-stent reste- nosis with a step-up phenomenon at the proximal edge of the BMS. The temporal WSS pattern in the region of the step-up showed existence of a region of flow separation with oscillating WSS [16].

Stone et al. [17] found an increase in intimamedia thickness, a decrease in lumen radius, and an increase in endothelial shear stress (ESS) at all levels of baseline ESS in 6 stented arteries, but there was no difference in neointimal growth for the different shear stress regions within the BMSs [17].

García et al. [18] also observed a negative correlation between the WSS and an increase in wall thickness on the mid-right coronary artery in 7 patients after BMS implantation.

Using coronary angiography and IVUS, Papafaklis et al. [19] performed 3-dimensional artery and stent reconstruction in 14 patients at an 8-month follow-up after BMS implantation with or without adjunctive beta-vascular brachytherapy. They found that in-stent restenosis was inversely related to WSS after coronary artery stenting and that vascular brachytherapy diminished the inverse relationship between neointima thickness and WSS. These authors also emphasized that WSS cannot predict the exact locations of NIH in all cases, since the thickening does not necessarily occur in all regions where WSS is low and not all regions where WSS is high are spared from NIH (Table 1). 


\section{DES studies}

Van't Veer et al. [20] investigated physiological parameters at stent implantation and at a 6 -month follow-up in 20 sirolimus-eluting stents (SES) and 20 BMSs. In this study, the SES were considered to produce a more physiologically hemodynamic performance 6 months after the procedure due to the fact that they maintained lower WSS values when compared with the BMSs. This concept contrasts with the findings of previous studies.

With the exception of the articles published by Suzuki et al. [21] and Papafaklis et al. [22], where the WSS was not associated with NIH after implantation of SES, further data on straight vessels confirmed that the WSS determines neointimal formation in DESs [23-25].

In the study by Suzuki et al. [21], there was no correlation between NIH and WSS in a diabetic population 9 months after 11 SES and 9 BMSs, while Papafaklis et al. [22] demonstrated a significant inverse NIH to WSS relation in only 3 of 10 SES patients with an overall nonsignificant correlation 6 months after SES implantation. The explanation of the results of the previous study proposed the role of diabetes (it may amplify the NIH response), while both studies concluded that sirolimus can attenuate effectively the low WSS induced vascular cell migration and proliferation.

With regard to bifurcation lesions, in the same issue of the "Journal of Interventional Cardiology", Hu et al. [26] and Zhang et al. [27] demonstrated that DES implantation with a crush technique or provisional technique was associated with restenosis in the main branch and the degree of WSS reduction, i.e., with an immediate decrease of the WSS after stenting, but without achieving a low WSS. A baseline low WSS, which decreases minimally after percutaneous coronary intervention and recovers to its approximate baseline level, appeared to be the setting for restenosis. These authors concluded that the mechanism of prevention of restenosis in the side branch in the case of provisional stenting (without side-branch stent) works by increasing the WSS, while in the main branch, the mechanism of prevention of restenosis is secondary to drug elution. A case report has recently been published of restenosis in a straight vessel segment with a very high shear stress near the site of step-down phenomenon [28], raising the possibility of extremely high WSS being associated with restenosis at the distal edge of the DES (Table 2).

\section{BVS studies}

Investigating the effect of WSS on NIH after BVS implantation [29], the relationship between baseline WSS and 6-month neointimal thickness was much stronger in the optical coherence tomography-based, 3-dimensional reconstruction than in the IVUS-based calculation. In another BVS study, an inverse association between WSS and NIH was also conferred as a consequence of local hemodynamic milieu on vessel wall healing (Table 3) [30].

The majority of publications summarized in Tables 1-3 favor the concept that low and oscillating shear stress is associated with intimal hyperplasia, but provide conflicting data regarding the clinical endpoints. Observations on the relationship between clinical restenosis requiring revascularization and WSS are restricted to only 2 studies of bifurcation lesions and 2 case reports of straight vessel segments, which also reach opposite conclusions. In all other papers reviewed, intimal hyperplasia was used as a surrogate endpoint and not as a clinical one.

\section{Discussion}

While shear stress is applied mainly to the endothelium in native coronary arteries [31], after endothelial injury caused by the stent implantation the most important mechanosensing cells are the SMCs. An early experimental study by Sterpetti et al. [32] reports that vascular SMCs may sense shear stress and it directly inhibits their proliferation. Shear stress affects the migratory and proliferative responses of vascular SMCs via several pathways, and can be transformed from a contractile to synthetic phenotype [33, 34].

The average WSS is considered only approx. $1 \mathrm{~Pa}$ in coronary arteries, while the stretching effect of an implanted coronary stent can generate up to $3 \times 10^{5}$ times higher circumferential stress in the vessel wall (Fig. 2) [35].

According to the established mechanism described above, it is clear that fluid shear stress delivers mechanosignal transduction that leads to initiation of neointimal growth, but also circumferential stress induced by the stretching effect of the implanted stents, being much higher in magnitude, can play an important role in the stimulation of the phenotypic adaptation to a dedifferentiated synthetic state of SMCs. Although the 


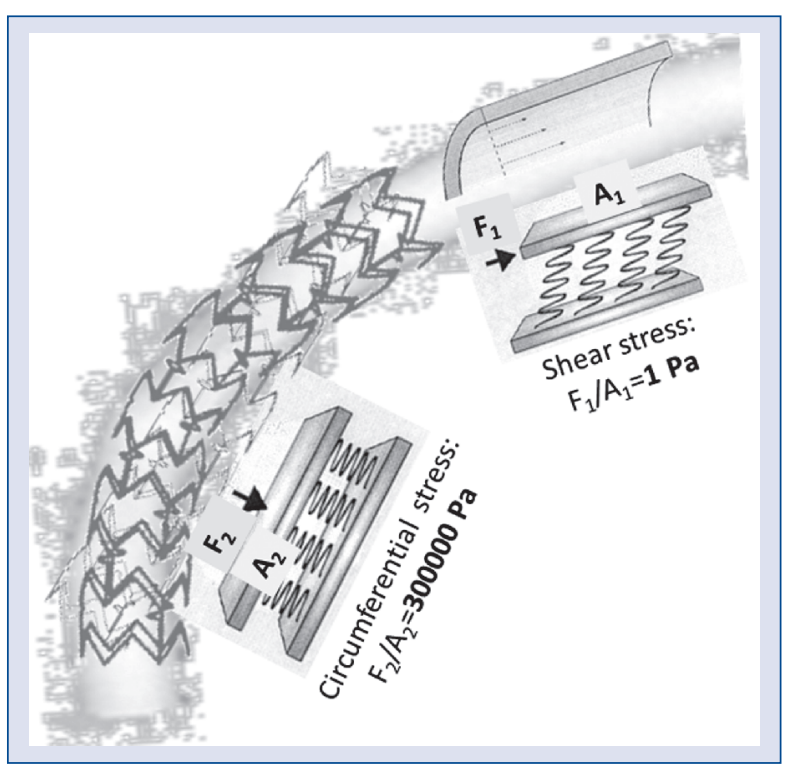

Figure 2. Fluid shear stress vs. circumferential wall stress: the flow results in wall shear stress in tangential direction. In the case of stent implantation to a narrowed coronary artery, wall stress will be generated by the stent which can reach a value of $300 \mathrm{kPa}$, being 5 orders of magnitude higher than the flow-generated shear stress.

mechanisms controlling the response of SMCs to mechanical stress have not been fully clarified, it seems that mechanical stretch is transmitted to the SMCs through macromolecular protein complexes, such as transmembrane integrins binding with intracellular adaptors (e.g., paxillin and vinculin) and signaling proteins (focal adhesion kinases) [36-38]. Macroscopically, stent placement induces straightening of arterial segments, slightly altering the distribution of shear stress. Microscopically, the local shear stress is mainly determined by the height of stent struts. A stent that protrudes into the lumen will alter the coronary flow, leading to changes in local shear stress distribution [39].

It is also crucial to comprehend that the newly regenerated endothelial layer is often dysfunctional [40]. This fact can play a key role in the restenotic process, when the uncontrolled neointimal formation is not stopped after the shear stress-induced "normal" re-endothelialization increased the flow velocity by decreasing the lumen diameter. In this case, the "autoregulation" is definitively destroyed and the exact mechanism responsible for the overshoot of the neointimal proliferation remains to be clarified.
However, restoration of the original geometry by stent implantation could theoretically re-establish the original WSS conditions that promoted de novo atherosclerosis formation. This mechanism does not seem obvious in the early restenotic process, but cannot be excluded in the background of late in-stent neoatherosclerosis.

Further technical issue in WSS calculation has arisen recently with regard to the modeling of side branches. As demonstrated by Li et al. [41], the average WSS was 4.64 Pa lower in the cases when side branches were taken into account than in the traditional straight vessel model. The studies cited in this review all used straight vessel segment calculation for the 3-dimensional reconstruction, therefore in the cases of pressure-based calculation they are hampered by this type of limitation.

The reviewed papers calculated the average shear stress inside the stented lumen rather than the microenvironment at the struts of the stents, therefore the ignorance of the stent reconstruction also could form an error source for the exact local shear stress calculation inside the stents. The right methodology would be to reconstruct both the lumen and the implanted stent, and use them both in the WSS calculation.

The complex relation between the flow shear stress and the restenotic process after stent implantation contributes to the difficulties of conducting observational studies. The follow-up intravascular imaging at a special time point could not provide right information about the whole process because the further prognosis usually could not be predicted on the basis of the investigation. Furthermore, the calculated shear stress is dependent on the applied boundary conditions, which are not patient-specifically incorporated in the modeling. The calculation show quite a wide range of shear stress (with a broad intermediate range) as in healthy vessels. This fact could limit the correlation of the shear stress with the observed intimal hyperplasia.

\section{Summary and future perspectives}

While the significance of WSS after stent implantation has been proved in neointimal formation, clinical restenosis endpoints are lacking. The lack of large-scale clinical endpoint studies is surprising, as there is a high number of wellcontrolled follow-up studies regarding the clinical results of different types of stent implantations, which theoretically can be evaluated even ret- 
rospectively using appropriate WSS assessment methods.

An adequately large number of patients is required to determine confounder-adjusted estimates. Longitudinal prospective studies after stent implantation with shear stress evaluation are also required for exploring deeper inside of the restenotic pathophysiology.

The available data raise the question of whether the detected NIH is a part of the healing process after stent implantation or a predictor of later clinical restenosis. Numerous other questions need to be answered for further research. Regarding WSS modeling, it is not clear at present whether an assumption of non-pulsatile steady flow provides enough information about the mechanism of restenosis after stent implantation. Even when the cyclic variation of the pulsatile flow is incorporated, it is still questionable whether we can analyze the flow alone without the stress and strain of a much higher magnitude inside the vessel wall as a consequence of the radial stretching of the implanted stent [42]. The rapid development of computational fluid dynamics methods provides a promise to elucidate the role of hemodynamic forces in the pathological processes of the formation of exaggerated intimal thickness after stent implantation.

\section{Conflict of interest: None declared}

\section{References}

1. Lu D, Kassab GS. Role of shear stress and stretch in vascular mechanobiology. J R Soc Interface, 2011; 8: 1379-1385.

2. Pedrigi RM, de Silva R, Bovens SM, Mehta VV, Petretto E, Krams R. Thin-cap fibroatheroma rupture is associated with a fine interplay of shear and wall stress. Arterioscler Thromb Vasc Biol, 2014; 34: 2224-2231.

3. Friedman MH, Bargeron CB, Deters OJ, Hutchins GM, Mark FF. Correlation between wall shear and intimal thickness at a coronary artery branch. Atherosclerosis, 1987; 68: 27-33.

4. Chatzizisis YS, Coskun AU, Jonas M et al. Role of endothelial shear stress in the natural history of coronary atherosclerosis and vascular remodeling: molecular, cellular, and vascular behavior. J Am Coll Cardiol, 2007; 49: 2379-2393.

5. Stone PH, Coskun AU, Kinlay S et al. Regions of low endothelial shear stress are sites where coronary plaque progress and vascular remodeling occurs in humans: An in-vivo serial study. Eur Heart J, 2007; 28: 705-710.

6. Samady H, Eshtehardi P, McDaniel MC et al. Coronary artery wall shear stress is associated with progression and transformation of atherosclerotic plaque and arterial remodeling in patients with coronary artery disease. Circulation, 2011; 124: 779-788.

7. Stone PH, Saito S, Takahashi S et al.; PREDICTION Investigators. Prediction of progression of coronary artery disease and clinical outcomes using vascular profiling of endothelial shear stress and arterial plaque characteristics: The PREDICTION Study. Circulation, 2012; 126: 172-181.
8. Peiffer V, Sherwin SJ, Weinberg PD. Does low and oscillatory wall shear stress correlate spatially with early atherosclerosis? A systematic review. Cardiovasc Res, 2013; 99: 242-250.

9. Rikhtegar F, Knight JA, Olgac U et al. Choosing the optimal wall shear parameter for the prediction of plaque location: A patientspecific computational study in human left coronary arteries. Atherosclerosis, 2012; 221: 432-437.

10. Mohamied Y, Rowland EM, Bailey EL, Sherwin SJ, Schwartz MA, Weinberg PD. Change of direction in the biomechanics of atherosclerosis. Ann Biomed Eng, 2015; 43: 16-25.

11. Casscells W. Migration of smooth muscle and endothelial cells. Critical events in restenosis. Circulation, 1992; 86: 723-729.

12. Balcells M, Martorell J, Olive C et al. Smooth muscle cells orchestrate the endothelial cell response to flow and injury. Circulation, 2010; 121: 2192-2199.

13. Carlier SG, van Damme LC, Blommerde CP et al. Augmentation of wall shear stress inhibits neointimal hyperplasia after stent implantation: Inhibition through reduction of inflammation? Circulation, 2003; 107: 2741-2746.

14. LaDisa JF Jr., Olson LE, Molthen RC et al. Alterations in wall shear stress predict sites of neointimal hyperplasia after stent implantation in rabbit iliac arteries. Am J Physiol Heart Circ Physiol, 2005; 288: H2465-H2475.

15. Wentzel JJ, Krams R, Schuurbiers JC et al. Relationship between neointimal thickness and shear stress after wallstent implantation in human coronary arteries. Circulation, 2001; 103: 1740-1745.

16. Thury A, Wentzel JJ, Vinke RV et al. Images in cardiovascular medicine. Focal in-stent restenosis near step-up: roles of low and oscillating shear stress? Circulation, 2002; 105: e185-e187.

17. Stone PH, Coskun AU, Kinlay S et al. Effect of endothelial shear stress on the progression of coronary artery disease, vascular remodeling, and in-stent restenosis in humans: In vivo 6-month follow-up study up study. Circulation, 2003; 108: 438-444.

18. García J, Crespo A, Goicolea J, Sanmartín M, García C. Study of the evolution of the shear stress on the restenosis after coronary angioplasty. J Biomech, 2006; 39: 799-805.

19. Papafaklis MI, Bourantas CV, Theodorakis PE, Katsouras CS, Fotiadis DI, Michalis LK. Relationship of shear stress with in-stent restenosis: bare metal stenting and the effect of brachytherapy. Int J Cardiol, 2009; 134: 25-32.

20. van't Veer M, Pijls NH, Aarnoudse W, Koolen JJ, van de Vosse FN. Evaluation of the haemodynamic characteristics of drug-eluting stents at implantation and at follow-up. Eur Heart J, 2006; 27: 1811-1817.

21. Suzuki N, Nanda H, Angiolillo DJ et al. Assessment of potential relationship between wall shear stress and arterial wall response after bare metal stent and sirolimus-eluting stent implantation in patients with diabetes mellitus. Int J Cardiovasc Imaging, 2008; 24: 357-364.

22. Papafaklis MI, Bourantas CV, Theodorakis PE et al. The effect of shear stress on neointimal response following sirolimus- and paclitaxel-eluting stent implantation compared with bare-metal stents in humans. J Am Coll Cardiol Cardiovasc Interv, 2010; 3: 1181-1189.

23. Bourantas CV, Räber L, Zaugg S et al. Impact of local endothelial shear stress on neointima and plaque following stent implantation in patients with ST-elevation myocardial infarction: A subgroup-analysis of the COMFORTABLE AMI-IBIS 4 trial. Int J Cardiol, 2015; 186: 178-185.

24. Papafaklis MI, Katsouras CS, Theodorakis PE, Bourantas CV, Fotiadis DI, Michalis LK. Coronary dilatation 10 weeks after paclitaxel-eluting stent implantation. No role of shear stress in lumen enlargement? Heart Vessels, 2007; 22: 268-273. 
25. Gijsen FJ, Oortman RM, Wentzel JJ et al. Usefulness of shear stress pattern in predicting neointima distribution in sirolimuseluting stents in coronary arteries. Am J Cardiol, 2003; 92: 1325-1328.

26. Hu ZY, Chen SL, Zhang JJ et al. Distribution and magnitude of shear stress after coronary bifurcation lesions stenting with the classical crush technique: a new predictor for in-stent restenosis. J Interv Cardiol, 2010; 23: 330-340.

27. Zhang JJ, Chen SL, Hu ZY et al. Contradictory shear stress distribution prevents restenosis after provisional stenting for bifurcation lesions. J Interv Cardiol, 2010; 23: 319-329.

28. Jenei C, Závodszky G, Paál G, Tar B, Kőszegi Z. High shear stress on the background of clinical restenosis at the site of stepdown phenomenon after drug eluting stent implantation. Cor et Vasa, 2015; doi: 10.1016/j.crvasa.2015.08.005

29. Papafaklis MI, Bourantas CV, Farooq V et al. In vivo assessment of the three-dimensional haemodynamic micro-environment following drug-eluting bioresorbable vascular scaffold implantation in a human coronary artery: Fusion of frequency domain optical coherence tomography and angiography. EuroIntervention, 2013; 9: 890 .

30. Bourantas CV, Papafaklis MI, Kotsia A et al. Effect of the endothelial shear stress patterns on neointimal proliferation following drug-eluting bioresorbable vascular scaffold implantation: An optical coherence tomography study. J Am Coll Cardiol Cardiovasc Interv, 2014; 7: 315-324.

31. Papaioannou TG, Stefanadis C. Vascular wall shear stress: Basic principles and methods. Hellenic J Cardiol, 2005; 46: 9-15.

32. Sterpetti AV, Cucina A, D'Angelo LS, Cardillo B, Cavallaro A. Shear stress modulates the proliferation rate, protein synthesis, and mitogenic activity of arterial smooth muscle cells. Surgery, 1993; 113: 691-699.
33. Jeremy JY, Rowe D, Emsley AM, Newby AC. Nitric oxide and the proliferation of vascular smooth muscle cells. Cardiovasc Res, 1999; 43: 580-594.

34. Hastings NE, Simmers MB, McDonald OG et al. Atherosclerosisprone hemodynamics differentially regulates endothelial and smooth muscle cell phenotypes and promotes pro-inflammatory priming. Am J Physiol Cell Physiol, 2007; 293: C1824-C1833.

35. Timmins LH, Meyer CA, Moreno MR, Moore JE Jr. Mechanical modeling of stents deployed in tapered arteries. Ann Biomed Eng, 2008; 36: 2042-2050.

36. Koskinas KC, Chatzizisis YS, Antoniadis AP, Giannoglou GD. Role of endothelial shear stress in stent restenosis and thrombosis: pathophysiologic mechanisms and implications for clinical translation. J Am Coll Cardiol, 2012; 59: 1337-1349.

37. Chaabane C, Otsuka F, Virmani R, Bochaton-Piallat ML. Biological responses in stented arteries. Cardiovasc Res, 2013; 99: 353-363.

38. Anwar MA, Shalhoub J, Lim CS, Gohel MS, Davies AH. The effect of pressure-induced mechanical stretch on vascular wall differential gene expression. J Vasc Res, 2012; 49: 463-478.

39. Van der Heiden K, Gijsen FJ, Narracott A et al. The effects of stenting on shear stress: relevance to endothelial injury and repair. Cardiovasc Res, 2013; 99: 269-275.

40. Tahir H, Bona-Casas C, Hoekstra AG. Modelling the effect of a functional endothelium on the development of in-stent restenosis. PLoS One, 2013; 8: e66138.

41. Li Y, Gutiérrez-Chico JL, Holm NR et al. Impact of side branch modeling on computation of endothelial shear stress in coronary artery disease: coronary tree reconstruction by fusion of $3 \mathrm{D}$ angiography and OCT. J Am Coll Cardiol, 2015; 66: 125-135.

42. Zhang JM, Zhong L, Su B et al. Perspective on CFD studies of coronary artery disease lesions and hemodynamics: a review. Int J Numer Method Biomed Eng, 2014; 30: 659-680. 